\title{
Effectiveness of Information Booklet on Knowledge \& Practice about Prevention of Pneumonia among Mothers of Under Five Children
}

\author{
Mamata Jena ${ }^{1}$ (M.Sc. Nursing) \\ Lecturer, Dept. of paediatricnursing,SUM NursingCollege, SOA University, Sector-8, Kalinganagar, Ghatikia, \\ Bhubaneswar- 751003 , Odisha, India
}

\begin{abstract}
Childhood pneumonia is one of the leadingcause of mortality in children aged less than five years. Mothers are the primary care giver, if they would possess adequate knowledge regarding prevention of pneumonia through information booklet then they can apply the same in their practice. Main objective of the study was to assess the effectiveness of information booklet on knowledge \& practice about prevention of pneumonia among mothers of under five children admitted to paediatric ward of a selected hospital of Odisha. Pre-experimental one group pre test and post test research design was adopted in this study.50 mothers who met the inclusion criteria were selected as study subjects by using non-probability purposive sampling technique. Result of the study shows that 52\% of mothers had no knowledge regarding prevention of pneumonia. The ' $t$ ' value for knowledge \& practice test are $35.78 \& 14.68$ respectively which are much greater than 1 (49) at 0.05 significance level(2.01) inboth indicating effectiveness of information booklet in increasing knowledge \& knowledge on practice. The calculated ' $r$ ' value of post test knowledge and practice scores i.e. 0.2783 indicating positive significant relationship i.e.r (48)>0.273 significance at 0.05 level. The study has implications in various fields of nursing \& based on the findings many recommendations were made for future research.
\end{abstract}

Keywords: Knowledge, Mothers of under five children, Pneumonia, Practice, Prevention

\section{Introduction}

We never stand so tall as when we stop to help a child. (Abraham Lincoln)

Approximately 150 million new cases of pneumonia occurs annually among children younger than five years worldwide, accounting for approximately 10-20 million hospitalizations. In India an estimated 25 million babies born annually and of these $24 \%$ (6 million) succumb to death. 7 out of every 10 of these are die due toacute respiratory infections. The incidence of clinical pneumonia in developing countries range between 2030\%.Millenium Development Goal (MDG), (1990-2015) increasing focus on the reduction of under five mortality rate by two thirds.Edwin S G et al (2004)conducted a study regarding the effectiveness of planned teaching programme (PTP) on knowledge, attitude and knowledge on practice of acute respiratory infections among mothers and found that there was a gross inadequacy (100\%) of knowledge regarding ARIs among the mothers \& PTP was found to be effective. HaryCambell et al (May 2008) conducted a study on epidemiology and etiology of childhood pneumonia on 15 countries stated that the estimated incidence is 0.37 episodes per child per year (e/cy) in India. Bulletin of $\mathrm{WHO}(2008)$ estimated that the incidence of childhood pneumonia among the under five children are about 156 million new episodes each year worldwide, of which 151 million episodes are in the developing world \& in India it is about 43 million. Park et al (2010),approximately 2 million death occurs due to pneumonia among the under five children.

Pneumonia is the inflammation of the lung parenchyma characterized by cough, sore throat, running nose, fast \& difficulty breathing, wheezing, fever, irritability, chest pain, chill, tachycardia etc. It is one of the major reason for which children are brought to the hospitals and health facilities. Most children have 3 to 5 attacks of ARI in each year. Prognosis of pneumonia is good in early diagnosis \& early initiation of treatment in appropriate time otherwise leads to serious complications and may have fatal outcome. As prevention is better thancure, the rate of incidence can be reduced by giving adequate knowledge regarding the risk factors, etiology, clinicalmanifestation, prevention\& when to seek medical help.

Mothers are the primary care givers of the child, so they need to be sufficiently aware regarding prevention of pneumonia. Though they have some knowledge regarding home management of cough, they did not practised it correctly. If mothers would possessappropriate knowledge, they can utilize this in a proper manner and improve their practice on the home management of cough and prevention of pneumonia, thereby decreasing the burden of the disease at the community and helps in social reconstruction. A printing material like information booklet with adequate key concepts regarding prevention of pneumonia can be given to the mothers expecting a positive outcome and by keeping with they would definitely get benefits from it. 
The review of literature and working area suggested that the rate of incidence of childhoodpneumonia can be reduced by creating awareness among the mothers of under five and this inspired the present study.

I.1.Statement of problem:-Effectiveness of information booklet on knowledge \& practice about prevention of pneumonia among mothers of under five children admitted to pediatric ward of M.K.C.G M.C.H, Berhampur, Odisha.

I.2. Objectives:-The study aimed to:-

(a) Assess the knowledge of the mothers of under fivechildren on prevention of pneumonia before and after administration of information booklet.

(b) Assess the practice of mothers of under five children on prevention of pneumonia before and after administration of information booklet.

(c) Develop an information booklet on prevention of pneumonia for the mothers of under five children.

(d) Determine the relationship between the post test knowledge and practices of the mothers of under five children on prevention of pneumonia.

\section{I.3.Hypotheses:-}

$\mathrm{H}_{1}$ :- Themean posttest knowledge scores of the mothers of under five children regarding prevention of pneumonia will be significantly higher than the mean pretest knowledge scores, as evident from structured questionnaire at 0.05 level of significance.

$\mathrm{H}_{2}$ :-The mean posttest practice scores of the mothers of under five children regarding prevention of pneumonia will be significantly higher than the mean pretest practice scores, as evident from practice scale at 0.05 level of significance.

$\mathrm{H}_{3}$ :-There will be asignificant positive relationship between posttest knowledge and posttest practice scores of mothers of under five children regarding prevention of pneumonia as evident from knowledge questionnaire and practice scale at 0.05 level of significance.

The conceptual framework of this study was based on Sister Callista Roy, s Adaptation Model (1964).

\section{Methodology}

II.1.Research approach: -The research approach adopted for the study was evaluative type and the research design selected was pre-experimental one group pretest and posttest design. The setting for the studyis pediatric ward of M.K.C.G Medical college hospital, Odisha.

II.2.Variables:-In this study the independent variable is information booklet and dependent variables are knowledge \& practice of the mothers regarding prevention of pneumonia.

II.3.Sample\& sampling technique:-The sample consists of 50 mothers of under five children admitted to pediatric ward selected byusing non probability purposive sampling technique.

II.4.Sample selection criteria:-

II.4.1. Inclusion criteria: -Mothers of under five children admitted to pediatric ward of a selected M.C.H, Odisha. Mothers who are willing to participate in the study.Mothers who can read and write Oriya and English.

II.4.2. Exclusion criteria:-Mothers of older chilldren. Mothers who were absent during data collection period.Mothers who cannot read Oriya.

II.5.Data collection tool and technique: -On the basis of conceptual framework and objectives of the study the following tools were developed to collect data.

II.5.1.Section-I: consists of 8 items of socio demographic data of the mothers such as age, educational qualification, occupation, family monthly income, type of family, religion, no. of under five children in the family, source of knowledge gained on prevention of pneumonia.

II.5.2. Section-II: consists of 25 items of multiple choice questions to assess the knowledge of the mothers \& the maximum possible score was 25 .

II.5.3. Section-III: consists of 17 items on a 3-point practice scale to assess the practice of the mothers\& the total score was ranged from 17 to 51 .

II.5.4. Section-IV: an information booklet on prevention of pneumonia.

II.6.Content validity of the tool and information booklet:-It was made by submitting to 7 experts for their opinion and suggestion. There was $100 \%$ agreement in the content with slight modification in some areas. After getting formal permission, a try out was done on 6 mothers who had similar characteristics to those sample subjects under the study to find reliability, feasibility and clarity and found that it is clear \& understandable. 
II.7.Reliability of the tools:-The reliability was measured by Split-half method and the reliability co-efficient of the knowledge questionnaire and practice scale were establishedby using Spearman Brown formula and found to be 0.87 and 0.76 respectively. Items were analyzed in terms of item difficulty and discrimination index and 5 items were modified which had values not within the acceptable range.

II.8.Pilot study:-It was conducted among 10 mothers of under five children in a selected hospital, data was analyzed and it revealed that it is feasible and practicable to conduct the final study.

II.9.Data collection procedure:-The data was collected from the sample subjects through the developed tools .The pre-test of knowledge and practice was taken on day-1 followed by distribution of information booklet and the post-test was conducted on day- 8 to assess the effectiveness of information booklet.

II.10. Plan for data analysis:-The descriptive and inferential statistics were used i.e. for demographic variables frequency and percentage \& for knowledge and practice component mean, median, standard deviation, paired ' $\mathrm{t}$ ' value \& co-efficient of correlation(r) were computed.

II.11. Ethical consideration:-The study was accepted by the research committee of College of nursing, Berhampur and ethical approval was taken from the Medical Superintendent, MKCG MCH, Berhampur. Ethical consent was taken from the mothers by giving information regarding the purpose of the study and confidentiality was maintained.

\section{Results And Discussions}

The collected data were edited, tabulated and analyzed by using descriptive and inferential statistics. The findingsrevealed the following:

- $72 \%$ of mothers were in the age group of $21-35$ years, $12 \% \& 16 \%$ were in age group of <20 years and >35 years respectively.

- $60 \%$ mothers were having educational qualification above matriculation where as only $40 \%$ had qualification of under matriculation.

- $70 \%$ mothers were housewife, $16 \%$ were daily workers, $6 \%$ were private employee, $4 \%$ had business and $4 \%$ were government employee.

- $\quad 76 \%$ mothers were having nuclear family, $20 \%$ had joint family and only $4 \%$ had extended family.

- $88 \%$ mothers belongs to Hindu religion, $8 \%$ were Christians and $4 \%$ were Muslims.

- $\quad 70 \%$ family had one child, $26 \%$ had two children and only $4 \%$ family had three and above children.

- More thanhalf(52\%) mothers had no knowledge regarding prevention of pneumonia where as $24 \%$ mothers gained knowledge from various mass media,20\% mothers gained knowledge from health professionals and only $4 \%$ mothers expressed that they had gained knowledge on prevention of pneumonia from their family

TABLE-1

Mean, Median and Standard deviation of pretest \& posttest knowledge scores of the mothers on prevention of pneumonia

$\mathbf{N}=\mathbf{5 0}$

\begin{tabular}{|l|l|l|l|l|}
\hline Knowledge test & Total score & Mean & Median & Standard deviation \\
\hline Pre test & 577 & 11.54 & 11.5 & 2.19 \\
\hline Post test & 997 & 19.94 & 20 & 2.11 \\
\hline
\end{tabular}

Maximum score $=25$

- TABLE-1reveals that the mean post testknowledge score(19.94) of the mothers of under five children on prevention of pneumonia was higher than their mean pretest knowledge score(11.54). The standard deviation of posttest (2.11) is less than pretest (2.19) which indicates that there is marked gain in knowledge in the posttest than pretest.

- The frequency polygonof the pre test and post test mean and median knowledge scores of the mothers shows that slight positive skewness with the mean on right side than median in pre test knowledge score and in the post test it shows slight negative skewness with the mean on left side than median.

- The cumulative percentage curve plotted in the same co-ordinated axis shows that the type post testOgive lies to the right of the pre testOgive over the entire range indicating that the post test knowledgescores were consistently higher than the pre test knowledge score.

- The pretest and posttest $25^{\text {th }}$ percentile of knowledge score were 9.5 and 18 respectively. $50^{\text {th }}$ percentile were 11 and $20 \& 75^{\text {th }}$ percentile were 14 and 22 respectively. The $25^{\text {th }}$ percentile of the posttest 18 falls beyond the $75^{\text {th }}$ percentile of pretest 14 which shows a marked gain in knowledge among the subject and effectiveness of the booklet in gaining knowledge. 
TABLE-2

Mean, Mean difference, Standard error of mean differenceand paired't' value of pretest and posttest knowledge score of the mothers of under five children

$\mathbf{N}=\mathbf{5 0}$

\begin{tabular}{|l|l|l|l|l|l|}
\hline Knowledge test & Mean & Mean difference & S $_{\text {EMD }}$ & 't' value & df \\
\cline { 1 - 2 } Pre test & 11.54 & & & \\
\cline { 1 - 2 } Post test & 19.94 & 1.66 & 35.78 & 49 \\
\hline
\end{tabular}

t (49) at 0.05 significance level $=2.01$

- TABLE-2 shows that the calculated ' $t$ ' value of 35.78 with a mean difference of 8.4 for df(49) was much greater than the table value of 't' at 0.05 significance level is 2.01 . Hence the research hypothesis $\mathrm{H}_{1}$ was accepted and null hypothesis $\mathrm{H}_{01}$ was rejected and it indicates the effectiveness of information booklet in increasing knowledge regarding prevention of pneumonia among the mothers of under five children.

TABLE-3

Mean Median and Standard deviation of pre test andpost test practice scores of the mothers of under five children on prevention of pneumonia

$\mathbf{N}=\mathbf{5 0}$

\begin{tabular}{|l|l|l|l|l|}
\hline Practice test & Total score & Mean & Median & Standard deviation \\
\hline Pre test & 1640 & 32.8 & 33 & 2.92 \\
\hline Post test & 2075 & 41.5 & 42 & 2.06 \\
\hline
\end{tabular}

Maximum score $=\mathbf{5 1}$

- TABLE-3 reveals that The mean posttest practice score (41.5) was higher than the mean pretest practice score (32.8) of the mothers of underfive children on prevention of pneumonia and the standard deviation of posttest was (2.06) which is less than the pretest (2.92) indicating an improvement in practice.

- The frequency polygon of pre test and post test mean and median practice scores shows the distribution was almost normal.

- The cumulative percentage curve depicts that the post testOgive lies to the right of the pre testOgive over the entire range indicating the post test practice scores were more than the pretest scores \& the distance separating the two curves at various levels revealed the increase in practice after utilization of information booklet.

TABLE-4

Mean, Meandifference, Standard error of mean difference and't' value of pre test and post test practice scores of the mothers of under five children on prevention of pneumonia

$\mathbf{N}=\mathbf{5 0}$

\begin{tabular}{|l|l|l|l|l|l|}
\hline Practice test & Mean & $\begin{array}{l}\text { Mean } \\
\text { difference(d) }\end{array}$ & S EMD & 't' value & Df \\
\hline Pre test & 32.8 & 8.68 & 4.179 & 14.68 & 49 \\
\hline Post test & 41.5 & & & \\
\hline
\end{tabular}

$t(49)=2.01$ at 0.05 significance level.

- TABLE-4 indicates thatthecalculated' $t$ ' value of 14.68 with a mean difference of 8.68 fordf (49) was much greater than the tabulated value of 2.01 at 0.05 level of significance. Hence the research hypothesis $\mathrm{H}_{2}$ was accepted and null hypothesis $\mathrm{H}_{\mathrm{O} 2}$ is rejected was inferred that the information booklet was effective in developing knowledge on practice of the mothers of under five children regarding prevention of pneumonia.

\section{TABLE-5}

Reliability co-efficient between post test knowledge and practice scores of the of under five children regarding prevention of pneumonia

$\mathbf{N}=\mathbf{5 0}$

\begin{tabular}{|c|l|l|l|l|l|l|}
\hline \multirow{2}{*}{ Test } & \multicolumn{2}{|c|}{ Knowledge score } & \multicolumn{2}{l|}{ Practice score } & \multirow{2}{*}{ r } & \multirow{2}{*}{ P } \\
\cline { 2 - 5 } & Mean & SD & Mean & SD & & \\
\hline Pre test & 11.54 & $\mathbf{2 . 1 9}$ & $\mathbf{3 2 . 8}$ & $\mathbf{2 . 9 2}$ & $\mathbf{0 . 0 6 3 8}$ & $\mathbf{0 . 0 5}$ \\
\hline Post test & 19.94 & $\mathbf{2 . 1 1}$ & $\mathbf{4 1 . 5}$ & $\mathbf{2 . 0 6}$ & $\mathbf{0 . 2 7 8 3}$ & \\
\hline
\end{tabular}

r (48)>0.273 significance at 0.05 level

- TABLE-5 shows that the calculated ' $r$ ' value of posttest score was 0.2783 indicated positive significant relationship between knowledge and practice at 0.05 level of significance. So, the null hypothesis $\mathrm{H}_{\mathrm{O} 3}$ was rejected \& the research hypothesis $\mathrm{H}_{3}$ was accepted showing the effectiveness of information booklet in increasing knowledge and practice of the mothers of under five children regarding prevention of pneumonia. 


\section{Conclusion}

During the pre test, the mothers lacked knowledge in most of the areas regarding prevention of pneumonia among the under five children. The study revealed that, if additional information in the form of booklet given to the mothers of under five children regarding various aspects of prevention of pneumonia, there would be enhanced awareness among them and it was helpful in increasing knowledge and develop better practices for home management of cough and seeks medical interventions as early as possible, thereby reducing child morbidity and mortality.

IV.1. Implication of the study: Nurses are the pivotal person to provide holistic care and educating the people by creating awareness thereby promoting their health status. They have a major role in evaluating and conducting research to continually improve methods which can adequately met society's needs. The results obtained from the study helped to provide certain implications for nursing, given as follows:-

IV.1.1. Nursing administration: The nurse administrator have responsibility to provide the nurses with substantive continuing educational opportunities and to motivate them to create awareness regarding childhoodpneumonia, health policies, developing protocol, procedures and striking orders related to childhood pneumonia.

IV.1.2. Nursingeducation: The nursing teachers can inculcate in the students the value of human life, the concept of primary health care, health promotion and prevention of under five pneumonia for reducing the under five mortality rate in the society.

IV.1.3. Nursing practice: All the nursing personnel working in the hospital and community health can be made aware about the risk factors, triggers, classification and clinical features of pneumonia and conduct mass and group health education programme by role playing or by using various teaching strategies like pamphlet, posters, booklet, leaflet etc. regarding different aspects of prevention of pneumonia.

IV.1.4.Nursing research: The effectiveness of the research study findings is verified by the utility of knowledge of the practicing nurses, which validate great contribution to the nursing professionand evidence based practice (EBP) can be implemented based on research findings.

IV.1.5. Professional organization: Conducting mass educational programme in collaboration with WHO, UNICEF and other national and international organizations regarding various aspects of prevention of pneumonia to create awareness in the community.

\section{IV.2. Limitation of the study:}

- The study was confined to a small group i.e. 50 numbers of the mothers of under five children admitted to pediatric ward of M. K. C. G,M.C.H, Berhampur, Odisha.

- The study sample was having at least one child under five years of age and the child may or may not be admitted at the paediatric ward.

- The sample being purposive was not true representative of the study population.

- The tool used in the present study was measure only the cognitive and psychomotor domain of the mothers of under five children regarding prevention of pneumonia.

\section{IV.3.Recommendations:}

- Similar studies can be done on a larger scale, in urban \& rural areas so as to compare children in selected districts.

- A study can be conducted using other strategies such as manual, computer assisted instruction, self instructionmodule, video show, planned teaching program etc.

- An experimental study can be conducted with control group among the mothers of under five children

- An exploratory study can be carried out to identify various factors responsible for deficient in knowledge and practice of mother regarding prevention of pneumonia among the under five children.

- A longitudinal study can be done using posttest after 1 month, 6 month and 1 year to see the retention of knowledge and practice.

- An information booklet can be prepared as a teaching aid in the hospitals and outpatient clinics.

\section{v. Acknowledgement}

I am highly obliged to all those who give constant inspiration, guidance, encouragement, support to make the study to be completed. Above all I offer my humble gratitude to "Almighty God "whose blessings empowered me with the celestial energy which increases self-confidence, develop self-control and compassion to complete this work successfully. 
Books:

\section{References}

[1] ClohertyJP, Sarthak A.R, Manual of Neonatal Care. $6^{\text {th }}$ ed (Newdelhi: Wolter Kluwer India Pvt. Ltd.2009) 299, 300. (8)

[2] Polit DF and Beck CT.Nursingresearch:Generating and Assessing Evidence for Nursing Practice. $8^{\text {th }}$ ed (New Delhi: Wolter Kluwer India Pvt.Ltd.2008) 272-571. (23)

[3] Whaley L.F and Wong D.L. Nursing Care of Infants and Children. $7^{\text {th }}$ ed (St. Louise: CV Mosby Company.2003).998-1010. (33)

Journals and Periodicals:

[4] A report by Secretariat, Treatment and Prevention of Pneumonia.WHO, 63rd World Health Assembly, 25thMarch.2010. (1)

[5] Bansal A ,SahaA,Zinc supplementation in severe acute lower respiratory tract infection in children :A triple blind randomized placebo controlled trial ,The Indian Journal of Paediatrics,Jan 2011;78(1),33-37.(3)

[6] Bhutta ZA. Childhood Pneumonia in developing countries.BMJ-2006, 333:612-613. (5)

[7] Sukumaran T V,Air pollution and child health ,Paediatric Today,Sept.Oct.2009,XII(5),196.(40)

\section{Miscellaneous:}

[8] http/www.whohomepage.com 